2-2015

\title{
Biogeography-based Optimization in Noisy Environments
}

\author{
Haiping Ma \\ Shaoxing University, mahp@usx.edu.cn \\ Minrui Fei \\ Shanghai University \\ Daniel J. Simon \\ Cleveland State University, d.j.simon@csuohio.edu \\ Zixiang Chen \\ Shaoxing University
}

Follow this and additional works at: https://engagedscholarship.csuohio.edu/enece_facpub

Part of the Electrical and Computer Engineering Commons

How does access to this work benefit you? Let us know!

\section{Original Citation}

H. Ma, M. Fei, D. Simon and Z. Chen, "Biogeography-based optimization in noisy environments," Transactions of the Institute of Measurement and Control, vol. 37, pp. 190-204, 2015.

\section{Repository Citation}

Ma, Haiping; Fei, Minrui; Simon, Daniel J.; and Chen, Zixiang, "Biogeography-based Optimization in Noisy Environments" (2015). Electrical Engineering \& Computer Science Faculty Publications. 328.

https://engagedscholarship.csuohio.edu/enece_facpub/328

This Article is brought to you for free and open access by the Electrical Engineering \& Computer Science Department at EngagedScholarship@CSU. It has been accepted for inclusion in Electrical Engineering \& Computer Science Faculty Publications by an authorized administrator of EngagedScholarship@CSU. For more information, please contact library.es@csuohio.edu. 


\section{Biogeography-Based Optimization with Blended Migration for Constrained Optimization Problems}

\author{
Haiping Ma \\ Shaoxing University \\ Shaoxing, Zhejiang, 312000, China \\ mahp@usx.edu.cn
}

\author{
Dan Simon \\ Cleveland State University \\ Cleveland, Ohio \\ d.j.simon@csuohio.edu
}

\begin{abstract}
Biogeography-based optimization (BBO) is a new evolutionary algorithm based on the science of biogeography. We propose two extensions to BBO. First, we propose blended migration. Second, we modify $\mathrm{BBO}$ to solve constrained optimization problems. The constrained $\mathrm{BBO}$ algorithm is compared with solutions based on a genetic algorithm (GA) and particle swarm optimization (PSO). Numerical results indicate that $\mathrm{BBO}$ generally performs better than GA and PSO in handling constrained single-objective optimization problems.
\end{abstract}

Categories and Subject Descriptors: G.1.6 [Numerical Analysis]: Optimization - constrained optimization; stochastic programming.

General Terms: Algorithms.

Keywords: evolutionary algorithm, biogeography-based optimization, constrained optimization.

\section{INTRODUCTION}

Many optimization problems in science and engineering have constraints. Evolutionary algorithms (EAs) have been successful for a wide range of constrained optimization problems [8].

Biogeography-based optimization (BBO) is a new evolutionary algorithm for global optimization that was introduced in 2008 [11]. It is modeled after the migration of species between habitats. One key feature of $\mathrm{BBO}$ is that the original population is not discarded after each generation. It is rather modified by migration. Another key feature is that BBO uses the fitness of each solution to determine its migration rates. $\mathrm{BBO}$ has demonstrated good performance on unconstrained benchmark functions [11]. It has also been applied to real-world optimization problems such as sensor selection [11], power system optimization [10], groundwater detection [4], and satellite image classification [9].

We propose two extensions to BBO. First, we use the blended crossover operator of the GA [6] to derive a blended migration operator for BBO. Second, we generalize BBO to constrained optimization problems. We adapt a method for constrained optimization which emphasizes the distinction between feasible and infeasible solutions in the search space [1], [3].

\section{BLENDED BBO}

In $\mathrm{BBO}$, there are two main operators: migration and mutation. We propose a new migration operator called blended migration, which is a generalization of the standard $\mathrm{BBO}$ migration operator, and which is motivated by blended crossover in GAs [6]. Blended migration is defined as

$$
H_{i}(s) \leftarrow \alpha H_{i}(s)+(1-\alpha) H_{j}(s)
$$

where $H_{i}$ is the $i$ th candidate solution in the BBO population, $s$ is its solution feature, and $\alpha$ is a real number between 0 and 1 . Equation (1) means that a solution feature of solution $H_{i}$ is not simply replaced by a feature from solution $H_{j}$. Instead, a new feature in a $\mathrm{BBO}$ solution is comprised of two components: the migration of a feature from another solution, and the migration of a feature from itself. The BBO algorithm, generalized for blended migration, is shown in Figure 1.

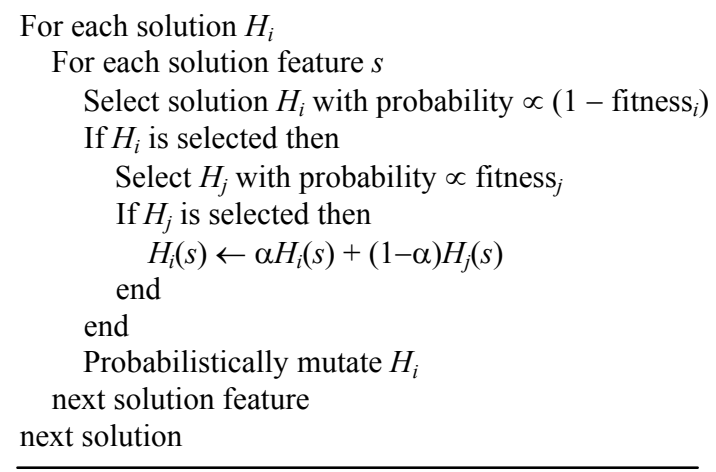

Figure 1. BBO Algorithm with fitness is normalized to $[0,1]$. $\alpha=0$ for standard BBO, and $\alpha>0$ for blended BBO.

\section{CONSTRAINED OPTIMIZATION}

In this paper we incorporate a method into BBO for constrainthandling based on feasibility rules which have demonstrated promising performance [1], [3]. Note from Figure 1 that the migration procedure modifies each solution to create a new solution. For constrained BBO, we check each solution to see if it is better than its version before migration. The new solution will replace its previous version only if it is better than its previous version. This is similar to a $(\mu+\lambda)$ evolutionary strategy where the next generation is chosen from both parents and children [2].

For constrained problems, when a solution $H_{1}$ is compared to a solution $\mathrm{H}_{2}$, solution $\mathrm{H}_{1}$ is considered better if and only if:

1) Both solutions are feasible, but $H_{1}$ has a cost that is less than or equal to that of $\mathrm{H}_{2}$; or,

2) $H_{1}$ is feasible and $H_{2}$ is not; or,

3) Both solutions are infeasible, but $H_{1}$ has a smaller overall constraint violation. 


\section{SIMULATION RESULTS}

We used a representative set of constrained benchmark functions to test the proposed approach [5], [7]. Simulation parameters were:

1) Population size: 50

2) Number of features per solution (problem dimension): 20

3) Mutation probability: 5\% per solution feature

4) Number of elite solutions per generation: 2

5) Maximum number of fitness function evaluations: 10,000

6) Number of Monte Carlo simulations per experiment: 30

Number of successes (NS) represents the number of simulations for which $f(x)-f_{\min } \leq 0.0001$ with feasible $x$, where $f_{\min }$ is the best known solution from [7]. We compare BBO, Blended BBO, GA, and PSO. The proposed constraint-handling method is adapted in an identical way for all four algorithms. Table 1 shows the results of solving the constrained benchmark functions. BBO outperforms GA and PSO on 8 of 13 benchmarks, and Blended BBO outperforms BBO on 10 of 13 benchmarks. This includes not only mean results and number of successes, but also standard deviation, which implies that $\mathrm{BBO}$ and blended $\mathrm{BBO}$ are more robust than GA and PSO.

We conclude that: (1) BBO is a competitive algorithm for solving constrained optimization problems; (2) constrained BBO outperforms GAs and PSO for the benchmark problems in this paper; and (3) Blended migration outperforms BBO.

Table 1. Results obtained on constrained benchmark problems: the mean solution found over 30 Monte Carlo simulations, the standard deviation of the $\mathbf{3 0}$ solutions, and the number of successes (NS). The best results are shown in red boldface.

\begin{tabular}{|c|c|c|c|c|c|c|c|c|c|c|c|c|}
\hline \multirow[b]{2}{*}{ Fn. } & \multicolumn{3}{|c|}{ BBO } & \multicolumn{3}{|c|}{ GA } & \multicolumn{3}{|c|}{ PSO } & \multicolumn{3}{|c|}{ Blended BBO } \\
\hline & Mean & Std Dev & NS & Mean & Std Dev & NS & Mean & Std Dev & NS & Mean & Std Dev & NS \\
\hline g01 & $1.1 \mathrm{E}-03$ & $4.7 \mathrm{E}-04$ & 20 & $3.5 \mathrm{E}-02$ & $8.4 \mathrm{E}-03$ & 15 & $2.9 \mathrm{E}-03$ & $4.4 \mathrm{E}-03$ & 15 & $2.7 \mathrm{E}-05$ & $9.0 \mathrm{E}-06$ & 30 \\
\hline g02 & 0.00 & 0.00 & 30 & $1.3 \mathrm{E}-01$ & $6.6 \mathrm{E}-01$ & 10 & $1.1 \mathrm{E}-02$ & $4.9 \mathrm{E}-02$ & 14 & 0.00 & 0.00 & 30 \\
\hline g03 & $3.3 \mathrm{E}-02$ & $8.3 \mathrm{E}-03$ & 12 & $2.7 \mathrm{E}-01$ & $7.9 \mathrm{E}-02$ & 10 & $2.8 \mathrm{E}-02$ & $6.0 \mathrm{E}-04$ & 12 & 3.1E-05 & $9.2 \mathrm{E}-05$ & 30 \\
\hline g04 & $1.3 \mathrm{E}+01$ & $9.4 \mathrm{E}+00$ & 0 & $3.0 \mathrm{E}+02$ & $1.8 \mathrm{E}+02$ & 0 & $3.9 \mathrm{E}+01$ & $3.5 \mathrm{E}+01$ & 0 & $2.5 \mathrm{E}+00$ & $3.2 \mathrm{E}+00$ & 2 \\
\hline g05 & $5.5 \mathrm{E}-08$ & $5.9 \mathrm{E}-07$ & 22 & $5.0 \mathrm{E}-06$ & $5.7 \mathrm{E}-05$ & 18 & $2.4 \mathrm{E}-01$ & $1.1 \mathrm{E}-01$ & 4 & 8.5E-09 & $9.0 \mathrm{E}-09$ & 30 \\
\hline g06 & $3.0 \mathrm{E}-01$ & $4.1 \mathrm{E}-01$ & 16 & $9.0 \mathrm{E}+01$ & $8.7 \mathrm{E}+00$ & 6 & $2.1 \mathrm{E}-01$ & $5.9 \mathrm{E}-02$ & 18 & $1.4 \mathrm{E}-01$ & $5.2 \mathrm{E}-01$ & 16 \\
\hline g07 & $2.2 \mathrm{E}+00$ & $7.6 \mathrm{E}-01$ & 3 & $8.5 \mathrm{E}+00$ & $6.4 \mathrm{E}+00$ & 2 & $9.0 \mathrm{E}+00$ & $7.9 \mathrm{E}+00$ & 2 & $3.5 \mathrm{E}-01$ & $1.5 \mathrm{E}-01$ & 8 \\
\hline g08 & $5.8 \mathrm{E}-11$ & $4.4 \mathrm{E}-12$ & 30 & $1.0 \mathrm{E}-12$ & $2.6 E-13$ & 30 & $7.5 \mathrm{E}-08$ & $9.0 \mathrm{E}-08$ & 30 & 7.2E-12 & $2.6 \mathrm{E}-12$ & 30 \\
\hline g09 & 0.00 & 0.00 & 30 & $3.1 \mathrm{E}+00$ & $2.2 \mathrm{E}+00$ & 3 & $1.7 \mathrm{E}+00$ & $6.9 \mathrm{E}+00$ & 10 & 0.00 & 0.00 & 30 \\
\hline g10 & $7.4 \mathrm{E}+01$ & $9.0 \mathrm{E}+00$ & 5 & $9.2 \mathrm{E}+00$ & $2.4 \mathrm{E}+00$ & 3 & $3.9 \mathrm{E}+00$ & $1.9 \mathrm{E}+00$ & 5 & $5.5 \mathrm{E}+01$ & $1.9 \mathrm{E}+00$ & 1 \\
\hline g11 & 0.00 & 0.00 & 30 & 0.00 & 0.00 & 30 & $1.3 \mathrm{E}-03$ & $3.5 \mathrm{E}-03$ & 15 & 0.00 & 0.00 & 30 \\
\hline $\mathrm{g} 12$ & $3.8 \mathrm{E}-07$ & $6.1 \mathrm{E}-08$ & 30 & $1.4 \mathrm{E}-05$ & $5.4 \mathrm{E}-06$ & 15 & $7.8 \mathrm{E}-05$ & $9.9 \mathrm{E}-06$ & 22 & $8.5 E-08$ & $1.5 \mathrm{E}-08$ & 30 \\
\hline g13 & $2.9 \mathrm{E}-01$ & $2.4 \mathrm{E}-02$ & 7 & $9.2 \mathrm{E}+00$ & $1.0 \mathrm{E}-01$ & 7 & $1.8 \mathrm{E}+00$ & $8.4 \mathrm{E}-01$ & 7 & $5.7 \mathrm{E}-02$ & $3.2 \mathrm{E}-02$ & 10 \\
\hline
\end{tabular}

\section{ACKNOWLEDGMENTS}

This work was partially supported by the Zhejiang Provincial Natural Science Foundation of China under Grant Y1090866, and by Grant 0826124 from the National Science Foundation.

\section{REFERENCES}

[1] Deb, K. 2000. An efficient constraint handling method for genetic algorithms, Computer Methods in Applied Mechanics and Engineering. 186, 2-4 (June 2000), 311-338.

[2] Du, D., Simon, D., and Ergezer, M. 2009. Biogeography-based optimization combined with evolutionary strategy and immigration refusal. IEEE Conf. on Systems, Man, and Cybernetics (San Antonio, Texas, October 2009). 1023-1028.

[3] Huang, V., Qin, A., and Suganthan, P. 2006. Self-adaptive differential evolution algorithm for constrained real-parameter optimization. IEEE Congress on Evol. Comp. (Vancouver, Canada, July 2006). 17-24.

[4] Kundra, H., Kaur, A., and Panchal, V. 2009. An integrated approach to biogeography based optimization with case based reasoning for retrieving groundwater possibility. 8th Annual Asian Conference and Exhibition on Geospatial Information, Technology and Applications (Singapore, August 2009).

[5] Liang, J., Runarsson, T., Mezura-Montes, E., Clerc, M., Suganthan, P., Coello, C., and Deb, K. 2005. Problem definitions and evaluation criteria for the CEC 2006 special session on constrained real-parameter optimization. Technical Report, http://www3.ntu.edu.sg/home/EPNSugan.

[6] McTavish, T., and Restrepo, D. 2008. Evolving solutions: The genetic algorithm and evolution strategies for finding optimal parameters. In: Applications of Computational Intelligence in Biology, T. Smolinski, M. Milanova, and A. Hassanien, Eds. Springer, New York, 55-78.

[7] Mezura-Montes, E. and Palomeque-Oritiz, A. 2009. Parameter control in differential evolution for constrained optimization. IEEE Congress on Evol. Comp. (Trondheim, Norway, May 2009). 1375-1382.

[8] Michalewicz, Z. and Schoenauer, M. 1996. Evolutionary algorithms for constrained parameter optimization problems. Evolutionary Computation. 4, 1 (Spring 1996), 1-32.

[9] Panchal, V., Singh, P., Kaur, N., and Kundra, H. 2009. Biogeography based satellite image classification. Int. J. Computer Science and Information Security. 6, 2 (Nov. 2009), 269-274.

[10] Rarick, R., Simon, D., Villaseca, F. E., and Vyakaranam, B. 2009. Biogeography-based optimization and the solution of the power flow problem, In Proceedings of the IEEE Conf. on Systems, Man, and Cybernetics (San Antonio, Texas, October 2009). 1029-1034.

[11] Simon, D. 2008. Biogeography-based optimization. IEEE Trans. on Evolutionary Computation. 12, 6 (Dec. 2008), 702713. 